\author{
Luiz Mello \\ Universidade Federal de Goiás (UFG) \\ Rezende Bruno de Avelar \\ Universidade Federal de Goiás (UFG) \\ Walderes Brito \\ Universidade Federal de Goiás (UFG)
}

\title{
Políticas públicas de segurança para a população LGBT no Brasil
}

Resumo: Neste artigo, apresenta-se uma análise crítica de ações, planos e programas governamentais, no campo da segurança pública, voltados para a população LGBT, no Brasil. A despeito da identificação de muitas propostas e de algumas iniciativas em curso, parte delas elaborada em espaços de discussão pública envolvendo governo e sociedade civil, o balanço final aponta absoluto desequilíbrio entre a violência homofóbica e a atuação do governo brasileiro para mudar este quadro. Tal constatação auxilia na compreensão da desconfiança de pessoas LGBT em relação ao Estado e a suas/seus representantes, em vários âmbitos da vida social em que direitos civis Ihes são negados, mas especialmente na esfera da segurança pública, em que o nexo entre questionamento da norma heterossexual e violência ainda é recorrente. Palavras-chave: segurança pública; LGBT; homofobia; políticas públicas; Brasil.

Copyright (c) 2014 by Revista Estudos Feministas.

'Agradecemos às/aos pareceristas que apreciaram a primeira versão do artigo enviado ao comitê editorial da revista Estudos Feministas e que apresentaram valiosas e oportunas sugestões. A responsabilidade por eventuais equívocos e lacunas no texto, claro, é nossa. ${ }^{2}$ Esse projeto foi desenvolvido no âmbito das atividades do Ser-Tão, Núcleo de Estudos e Pesquisas em Gênero e Sexualidade, da Universidade Federal de Goiás, e contou com apoio financeiro da Secre-
Este texto' apresenta os resultados da pesquisa Políticas públicas para a população LGBT no Brasil: um mapeamento crítico preliminar, ${ }^{2}$ particularmente quanto ao tema da segurança pública. Baseia-se em informações coletadas por meio de levantamento documental e entrevistas, realizadas entre setembro de 2009 e fevereiro de 2010, com 43 ativistas e 52 gestoras/es de nove estados brasileiros $^{3}$ e do Distrito Federal, com atuação nos níveis municipal, estadual e federal (Tabela 1). 
Tabela 1: Quantidade, por unidade de federação, de ativistas e gestoras/es estrevistadas/os

\begin{tabular}{l|c|ccc|c}
\hline $\begin{array}{l}\text { Unidades } \\
\text { da Federação }\end{array}$ & Ativistas & Federais & $\begin{array}{l}\text { Gestoras } \\
\text { Estaduais }\end{array}$ & Municipais & Total \\
\hline Amazonas & 5 & - & 2 & - & 7 \\
Ceará & 4 & - & 2 & 2 & 8 \\
Distrito Federal & 6 & 12 & 4 & - & 22 \\
Goiás & 3 & - & 4 & - & 7 \\
Pará & 3 & - & 3 & - & 6 \\
Paraná & 3 & - & 2 & 1 & 6 \\
Piauí & 2 & - & 5 & - & 7 \\
Rio de Janeiro & 7 & - & 5 & 1 & 13 \\
Rio Grande do Sul & 5 & - & 1 & 2 & 8 \\
São Paulo & 5 & - & 4 & 2 & 11 \\
\hline Total & 43 & 12 & 32 & 8 & 95 \\
\hline
\end{tabular}

Fonte: Elaborada pelos autores, 2010.

taria de Direitos Humanos, da Presidência da República (SEDH/ PR) e da Fundação de Amparo à Pesquisa do Estado de Goiás (Fapeg).

${ }^{3}$ Amazonas, Ceará, Goiás, Pará, Paraná, Piauí, Rio de Janeiro, Rio Grande do Sul e São Paulo.

${ }^{4}$ Luiz MELLO et al., 2011.

${ }^{5}$ Não há consensos no que tange aos modos de se nominar o movimento social organizado em torno de questões relativas às homossexualidades, travestilidades e transexualidades, no Brasil (Regina FACCHINI, 2005). Utiliza-se aqui, provisoriamente, a expressão LGBT (lésbicas, gays, bissexuais, travestis e transexuais), uma vez que esta tem sido muito utilizada por estudos recentes, desde que foi aprovada na I Conferência Nacional LGBT, realizada em Brasília, em 2008 .
Além do critério regional, que levou à seleção de dois estados por região do país (Goiás e Distrito Federal correspondendo à Centro-Oeste), outra motivação para a seleção desses/as colaboradores/as foi a existência, no âmbito do Poder Executivo (estadual ou municipal), à época do início do trabalho de campo (agosto de 2009), de: a) coordenação/coordenadoria responsável pela execução de ações voltadas para a população LGBT; ou b) órgão responsável pelo atendimento das demandas, inclusive, de LGBT. Quando tais condições não foram plenamente satisfeitas, levou-se em consideração também a tradição de atuação de grupos de ativismo LGBT como um critério para a seleção de potenciais entrevistados/as. ${ }^{4}$

Neste texto, evita-se a apresentação de elementos de identificação individual (como idade, sexo, cor/raça, nível de escolaridade, local de moradia, vinculação profissional, orientação sexual, identidade de gênero, entre outros), bem como a utilização de trechos de entrevistas que permitam a identificação de entrevistados/as e/ou de sujeitos por eles/as mencionados/as.

O texto está estruturado em três partes principais: Aproximações conceituais, Em direção a um mapeamento de propostas e ações e Problemas e desafios.

\section{Aproximações conceituais}

A reivindicação de políticas públicas de segurança constitui, na atualidade, uma das principais demandas do movimento LGBT ${ }^{5}$ brasileiro. Tal movimento baseia-se na 
${ }^{6}$ BRASIL, 1989, p. 44.

${ }^{7}$ Natalia de Oliveira FONTOURA Patrícia Silveira RIVERO e Rute Imanishi RODRIGUES, 2009.

${ }^{8}$ FONTOURA, RIVERO \& RODRIGUES, 2009, p. 143.

9 Cynthia CIARALlo e Andréa NASCIMENTO, 2009.

\footnotetext{
10 BRASIL, 2014, p. 4.

${ }^{1}$ CIARALLO e NASCIMENTO, 2009.

12 Benedito Domingos MARIANO, 2009.

${ }^{13}$ Dados do Ministério da Saúde, que reproduzem levantamento feito ao longo de mais de duas décadas pelo Grupo Gay da Bahia e especialmente pelo antropólogo e ativista Luiz Mott, apontam que no Brasil foram assassinadas 2.51 homossexuais no período de 1980 a 2005, "[...] em sua maior parte vítimas de crimes homofóbicos: $72 \%$ eram gays, $25 \%$ travestis e $3 \%$ lésbicas [...]" (BRASIL, 2008a p. 22). De acordo com esses relatórios, deveriam ser referidos como crimes homofóbicos aqueles que têm como motivo a não aceitação e o ódio por parte do/a agressor/a em relação à vítima, devido à sua identidade de gênero e/ou orientação sexual, por ser ela gay. lésbica, travesti, transexual ou bissexual, englobando a humilhação, a ofensa e a extorsão (DHNET, 2010 e BRASIL, 2008b).
}

própria Constituição Federal, que reconhece a segurança como um dos direitos individuais fundamentais (artigo quinto, capuf) e também como direito social (artigo sexto, caput), definindo-a, no artigo 144, como dever do Estado e direito e responsabilidade de todos, visando à "[...] preservação da ordem pública e da incolumidade das pessoas e do patrimônio [...]". ${ }^{6}$

Segundo Natalia Fontoura, Patrícia Rivero e Rute Rodrigues, ${ }^{7}$ quando a Constituição Federal atribui ao Estado o dever de ofertar segurança pública, implica que este é um direito inalienável de todas/os as/os cidadãs/ãos. Por outro lado, as autoras refletem que o sentido constitucional da segurança pública como responsabilidade de todas/os deriva do reconhecimento da importância do papel da sociedade tanto na participação quanto no controle das políticas dessa natureza. A sociedade colabora com a segurança pública, ademais, atuando "[...] na socialização dos indivíduos, na perpetuação dos mecanismos informais de controle social e de autocontrole, a partir da perspectiva de que não é somente o controle pelo Estado que garante a segurança de todos [...]". ${ }^{8}$

Segundo Ciarallo e Nascimento, ${ }^{9}$ nos últimos anos, a participação popular na área da segurança pública ganhou impulso com a criação dos conselhos de segurança pública em todas as instâncias governamentais e com a edição do Programa de Segurança com Cidadania (Pronasci), que "[...] articula políticas de segurança com ações sociais; prioriza a prevenção e busca atingir as causas que levam à violência, sem abrir mão das estratégias de ordenamento social [...] [e segurança pública]". ${ }^{10}$

Menos otimista do que Ciarallo e Nascimento, ${ }^{11}$ Mariano ${ }^{12}$ é bastante cético sobre melhorias na área de segurança pública. Para este autor, os avanços a partir da Constituição Federal de 1988 são visíveis quanto aos direitos civis e políticos, bem como no âmbito dos direitos coletivos. Já em relação ao setor de segurança pública, sua opinião é que não há grande diferença quando se compara o artigo 144 da atual Constituição com os artigos correspondentes da Constituição Federal do regime militar, de 1967.

Para além do embasamento constitucional, quando se foca o olhar sobre a população de lésbicas, gays, bissexuais, travestis e transexuais (LGBT), questões como violência e segurança pública passam a ser complexificadas a partir da noção de homofobia, que tem sido capitaneada pelo movimento social com a intenção de reivindicar políticas públicas nessas áreas. ${ }^{13}$ Segundo Daniel Borrillo, o termo homofobia pode ser conceituado como 
${ }^{14}$ Daniel BORRILLO, 2001, p. 36.

\footnotetext{
${ }^{15}$ BRASIL, $2013 a$.
}

[...] la hostilidad general, psicológica y social, respecto a aquellos y aquellas de quienes se supone que desean a individuos de su propio sexo o tienen practicas sexuales con ellos. Forma específica del sexismo, la homofobia rechaza también a todos los que no se conforman con el papel predeterminado por su sexo biológico. Construcción ideológica consistente en la promoción de una forma de sexualidad (hetero) en detrimento de otra (homo), la homofobia organiza una jerarquización de las sexualidades y extrae de ella consecuencias políticas. ${ }^{14}$

Originalmente criado a partir do campo da psicologia, uma das dificuldades na utilização do termo sociologicamente parece dizer respeito à ênfase no aspecto individual, além do que a adoção do sufixo 'fobia' para caracterizar qualquer modalidade de preconceito e discriminação sexual e de gênero pode reforçar um discurso biológico e patologizante, quando se sabe que os fundamentos das disputas de poder entre grupos diversos, inclusive sexuais, são claramente de ordem social, política, cultural e econômica. Não há consensos, contudo, no que tange às alternativas conceituais ao termo. É possível, de todo modo, ao se reportar à questão da segurança pública, falar nos diversos preconceitos e discriminações, bem como às violências (nas diversas acepções do termo e em seus múltiplos efeitos físicos, materiais e simbólicos) dirigidas contra a população LGBT. Será mantido o uso de homofobia neste texto sempre que a expressão integrar nomes de eventos ou for referida em documentos citados e entrevistas realizadas com gestoras/es e ativistas no contexto da pesquisa.

Especificamente no contexto brasileiro, a Secretaria de Direitos Humanos da Presidência da República (SDH) apresentou duas versões do Relatório sobre violência homofóbica no Brasil: o ano de 2011/ano de 2012, que são os primeiros estudos oficiais sobre o tema não apenas no Brasil, mas em toda a América Latina, ${ }^{15}$ elaborado com informações consolidadas especialmente a partir de denúncias provenientes do Disque Direitos Humanos (Disque 100). Publicados no ano de 2012 e 2013, esses relatórios são uma menção obrigatória em reflexões sobre segurança pública para este segmento, antes de tudo porque reúnem os primeiros dados produzidos por um canal oficial do governo brasileiro e depois pelo fato de registrarem violências contra LGBT que não se limitam à forma extrema do homicídio. Os dados informados, entretanto, como a própria versão inaugural do relatório reconhece, estão longe de retratar a realidade de violação de direitos humanos em curso, em grande medida porque os canais de registro de informação dessa natureza são frágeis. Dividido em duas seções principais, esse relatório apresenta primeiro os dados 
$\left.{ }^{16} 1\right)$ 'Disque 100', ou Disque Direitos Humanos, da Secretaria de Direitos Humanos; 2) o 'Ligue 180', ou Central de Atendimento à MuIher, da Secretaria de Políticas para as Mulheres, ambas sendo secretarias da Presidência da República; 3) o 'Disque Saúde' e Ouvidoria do SUS, do Ministério da Saúde; 4) comunicações diretas para o Conselho Nacional de Combate à Discriminação e para a Coordenação Geral de Promoção dos Direitos de LGBT.

${ }^{17}$ BRASIL, 2012.

${ }^{18}$ BRASIL, 2013a.

${ }^{19}$ BRASIL, $2013 a$.

20 BRASIL, 2012.

${ }^{21}$ BRASIL, 2013a.

22 BRASIL, 2012.

${ }^{23}$ BRASIL, $2013 \mathrm{a}$.

${ }^{24}$ BRASIL, 2012.

${ }^{25}$ BRASIL, 2013a.

${ }^{26}$ BRASIL, 2012.

${ }^{27}$ BRASIL, $2013 \mathrm{a}$. coletados em quatro canais disponíveis na estrutura do Governo Federal ${ }^{16} \mathrm{e}$, em seguida, assume uma metodologia e um serviço prestado há pelo menos três décadas pelo Grupo Gay da Bahia (GGB), que consiste no inventário de crimes conta LGBT noticiados pela mídia.

A primeira parte dos estudos tem como base o registro de 1.159 denúncias, relativas a 6.809 violações de direitos humanos contra LGBTs denunciadas ao Governo Federal em 2011 , envolvendo 1.713 vítimas e 2.275 suspeitos. ${ }^{17} \mathrm{Em}$ 2012 , o número de denúncias chegou a 3.084 , com 9.982 violações, 4.851 vítimas e 4.784 suspeitos, o que corresponde a aumentos respectivos de 166,9\%, 46,6\%, 183,19\% e $110,19 \%$, comparando os dados de 2011 e $2012 .{ }^{18}$

Como o relatório adverte, por um lado, esses dados não expressam plenamente a realidade de violência, que é reconhecidamente subnotificada, e, por outro, os percentuais não indicam, necessariamente, um aumento da violência focado no ano de 2012, mas talvez um maior conhecimento do canal de denúncia, estimulado tanto pela Conferência Nacional LGBT (2012) quanto pela própria repercussão da primeira versão do relatório. Outro aspecto que pode ser interpretado positivamente é o fato de a maioria das denúncias de 2012 ter sido feita por pessoas que presenciaram, mas não conhecem as vítimas $\left(47,3 \%\right.$ dos casos), ${ }^{19}$ o que pode indicar uma rejeição social progressiva em relação às práticas preconceituosas contra LGBT.

Considerando as predominâncias estatísticas e os aspectos demográficos coincidentes nas duas pesquisas, sexo, etnia e geração são marcadores que se confirmam, sendo a maior parte das vítimas dessas violações identificada como pessoas do sexo biológico masculino $(67,5 \%$ em $2011 ;{ }^{20}$ e $71,38 \%$ em 2012), ${ }^{21}$ são negras (51,1\% em $2011 ;{ }^{22}$ e $40,55 \%$ em 2012), ${ }^{23}$ jovens (47,1\% com idade entre 15 e 29 anos, em $2011 ; 24$ e $61,16 \%$ em 2012). ${ }^{25}$

Por outro lado, as pesquisas apresentam discrepâncias em dois aspectos cruciais: o primeiro diz respeito à orientação sexual das vítimas, que, em 2011 , teve a maioria identificada como homossexuais (85\%), ${ }^{26}$ enquanto que, em 2012 , o polo se inverteu, com $82 \%$ das vítimas não tendo a sua orientação sexual identificada. ${ }^{27}$ Também são discrepantes os números relativos à identidade de gênero, tendo sido a maioria das vítimas identificada como lésbicas em 2011 $(34,5 \%)$ e como gays em $2012(60,44 \%)$. O relatório reconhece, entretanto, que este dado é bastante impreciso, uma vez que categorias 'identidade de gênero' e 'orientação sexual' não são domínio geral, o que amplia o risco de invisibilização, principalmente das violências transfóbicas.

Quanto aos agressores, entre as duas pesquisas, foi predominante a afirmação de que são pessoas conhecidas 
${ }^{28}$ BRASIL, 2012.

${ }^{29}$ BRASIL 2013a.

${ }^{30}$ BRASIL, 2012

${ }^{31}$ BRASIL, 2013a.

${ }^{32}$ BRASIL, 2012 e BRASIL, $2013 a$.

${ }^{33}$ BRASIL, 2012

${ }^{34}$ BRASIL, $2013 a$.

${ }^{35}$ BRASIL, 2012.

${ }^{36}$ BRASIL, $2013 a$

${ }^{37}$ BRASIL, 2012.

${ }^{38}$ BRASIL, 2012.

${ }^{39}$ BRASIL, 2013a. das vítimas $(61,9 \%$ dos casos denunciados em $2011 ; 28$ e $58,9 \%$ em 2012 , sendo principalmente familiares e vizinhos em ambos casos. ${ }^{29}$ Nas denúncias feitas aos canais do Governo Federal, as violações acontecem tanto em casa quanto na rua $\left(42 \%\right.$ e $30,8 \%$, respectivamente, em $2011 ;^{30} \mathrm{e}$ $38,63 \%$ e $30,89 \%$ em 2012$)^{31}$ e os casos mais frequentes tipificados são de violência psicológica (42,5\% e 83,2\%), discriminação $(74,01 \%)$ e violência física $(32,68 \%){ }^{32}$

A segunda parte do relatório, baseada em dados hemerográficos, afirma um pouco da realidade de violação de direitos contra LGBT, mas talvez expresse muito mais a conduta da mídia diante desses casos, frequentemente invisibilizados sob a alegação de que não têm "valornotícia", reforçando a predominante naturalização da violência sexista e homofóbica. O aspecto mais discrepante entre os dados obtidos por denúncia direta e os obtidos através da imprensa diz respeito justamente à tipificação das violações. Enquanto, nas denúncias feitas ao governo federal, a violência física ocupou a terceira posição, na imprensa majoritariamente são noticiados esses tipos de caso $(73,4 \%$ das 478 violações noticiadas em $2011 ; 33$ e $74,56 \%$ dos casos noticiados em 2012),34 sendo quase oito, em cada 10 notícias, referentes a homicídios, ou seja, uma regra não escrita, mas tácita da imprensa, é que, se não for violência física, principalmente assassinato, as violações contra LGBT não precisam ser noticiadas.

O relatório chama a atenção, ainda, para dois aspectos relevantes: a invisibilidade de algumas vítimas e a letalidade dos crimes noticiados. As violências cometidas contra lésbicas, em 2011 , compuseram 7,3\% das vítimas identificadas em notícias veiculadas nos meios de comunicação; porém, chegaram a $34,5 \%$ das vítimas registradas nos canais disponibilizados pelo poder público. ${ }^{35}$ Os/as transexuais, por sua vez, sequer figuram nas notícias de violência veiculadas na mídia em 2012.36 Finalmente, os relatórios concluem que metade das vítimas fatais identificadas nas notícias veiculadas em 2011 era formada por travestis, ${ }^{37}$ que correspondem a $49 \%$ das pessoas assassinadas. ${ }^{38}$

Em 2012, mais uma vez a maioria das vítimas de violência em geral noticiadas $(51,86 \%)$ não foi maioria entre as pessoas assassinadas, mas ficou imediatamente abaixo dos gays $(54,19 \%){ }^{39}$

A partir das falas de entrevistados/as, salta aos olhos a percepção de que, embora necessárias e urgentes, as iniciativas com objetivo de coibir as violências contra a população LGBT, no Brasil, não têm tido a efetividade que as propostas de políticas públicas de segurança almejam. Na atualidade, o movimento social exige do poder público 
${ }^{40}$ Maria das Graças RUA, 1998.

${ }^{41}$ Neuza GUARESHI et al., 2004.
${ }^{42}$ Nos termos de Anthony GIDDENS (2002), são os processos e as açôes políticas que favorecem a autonomia e a independência de indivíduos e grupos explorados por outros, promovendo libertação em relação a realidades de dependência e desigualdades.

${ }^{43}$ Emerson Clayton Rosa SANTOS 2010. uma atuação mais ampla e permanente, que não esteja limitada às opções do governo da vez, mas que sejam políticas públicas efetivas, compreendidas, segundo Maria das Graças Rua, ${ }^{40}$ como conjunto de decisões e ações destinado à resolução de problemas políticos e de conflitos quanto ao acesso a bens públicos. Outras/os autoras/es, como Neuza Guareshi et al., ${ }^{41}$ destacam que as políticas públicas deveriam ser ações coletivas, no sentido de serem formuladas e executadas com a participação da sociedade, visando à garantia de direitos.

Ao reivindicarem a implementação e a execução de políticas públicas afirmativas e emancipatórias ${ }^{42}$ para a população LGBT, as/os ativistas disputam poder, interesses e posições na construção da agenda política e reivindicam espaço para acompanhá-las e monitorá-las, exercendo o controle social que legitima uma ação de governo. Um exemplo dessa disputa por espaço foi a participação de representantes da sociedade civil nas I e II Conferências Nacionais LGBT, convocadas pelo Governo Federal e realizadas em 2008 e 2011, respectivamente, ocasiões em que surgiram várias propostas no campo da segurança pública para todas as pessoas potencialmente vítimas de 'homofobia'. De acordo com Emerson Santos, ${ }^{43}$ essas propostas não se limitam ao combate da criminalidade, nem se restringem à atividade policial. Entre as 86 deliberações aprovadas para o campo da segurança na plenária final da I Conferência LGBT, há proposições que vão desde a criminalização dos atos de preconceito por orientação sexual até a ampliação do número de cursos de direitos humanos, mudanças no currículo de formação de policiais e atendimento qualificado da população BLGT e LGBT em qualquer delegacia, entre outras.

A necessidade de estabelecer políticas públicas de segurança se fundamentaria em tais documentos, a partir de noções como desrespeito, intolerância, impunidade e violência contra a população LGBT, e uma das formas pelas quais o movimento social tem buscado legitimar as demandas por segurança pública refere-se à ausência ou ao alcance limitado de uma legislação que garanta os direitos civis dessa população e que possibilite o exercício pleno da cidadania, bem como à difusão de um ideário de intolerância sexual, que se manifesta nos discursos de representantes de instituições diversas, como igrejas, parlamentos, partidos políticos e meios de comunicação de massa.

Um exemplo disso são os debates e disputas ideológicas em torno da aprovação do Projeto de Lei n. 122, de 2006, que tramita no Congresso Nacional há 13 anos, o qual prevê a criminalização da homofobia nos moldes da Lei $n$. 7.716, de 1989, que define os crimes resultantes de preconceito de raça ou de cor. Sinalizando a importância da 
44 Júlio Assis SIMÕES e Regina FACCHINI, 2009, p. 155.

${ }^{45}$ BRASIL, $2013 b$. aprovação dessa lei, Júlio Simões e Regina Facchini destacam:

A resistência ao projeto, expressa sobretudo por autoridades religiosas cristãs em aliança com psicólogos e médicos ligados a grupos religiosos evangélicos, tem se concentrado nas alegações de cerceamento da liberdade de expressão e em reiterados esforços de patologização e criminalização da homossexualidade, por meio de sua associação à pedofilia. ${ }^{44}$

Embora não haja tal legislação federal, há ações, projetos e programas que procuram minimizar os impactos das violências contra a população LGBT, tanto na esfera federal quanto nas estadual e municipal.

Um exemplo recente foi a instituição de um grupo de trabalho sobre a temática LGBT no âmbito da Secretaria Nacional de Segurança Pública, do Ministério da Justiça, com a finalidade de criar um desenho de boletim de ocorrência que permita caracterizar crimes homofóbicos em todo o país, além de garantir a utilização do nome social no caso de travestis e transexuais. Ainda nessa direção, é relevante mencionar o anúncio do apoio do Ministro da Justiça, José Eduardo Cardozo, à aprovação do PLC 122/06, que trata da criminalização da homofobia. ${ }^{45}$

De acordo com os/as entrevistados/as, não há clareza, entretanto, sobre os avanços dessas iniciativas, muito menos sobre o que de fato foi efetivado no campo da segurança pública. Também se sabe pouco a respeito da interação do governo com o movimento LGBT, tanto na elaboração quanto na execução e controle das políticas delineadas. Procura-se tratar dessas e de outras questões nas entrevistas realizadas com gestoras/es e ativistas, sendo suas respostas o ponto de partida para as reflexões sobre políticas públicas de segurança voltadas para a população LGBT apresentadas a seguir.

\section{Em direção a um mapeamento de propostas e ações}

Das 95 pessoas entrevistadas na pesquisa, aproximadamente $55 \%$ abordaram o tema segurança pública, que é particularmente apontado como relevante por ativistas. Refletindo sobre conquistas na área da segurança pública para a população LGBT de um modo geral, um/a ativista ${ }^{46}$ fez um balanço positivo, comparando a violência dos anos de 1970 com a dos dias atuais. Segundo ele/a, antes as/os 'homossexuais' tinham mais problemas com a polícia e com a violência social do que hoje. Embora reconheça que a situação ainda está longe da ideal, essa/e ativista enfatiza que já se consegue ver travestis trabalhando na rua sem 
passar por grandes problemas e gays assumidos exercendo cargos administrativos no Legislativo, no Executivo e no Judiciário, por exemplo.

De um modo geral, entretanto, o quadro pintado pelas/os entrevistadas/os a respeito da violência que atinge a população LGBT no Brasil ainda é bastante negativo, como refletem ativistas que atuam em cidades diversas e que situam os problemas de segurança pública LGBT no contexto de violência que afeta a população em geral. Na percepção de um/a desses/as ativistas, a sociedade brasileira é violenta, mata as pessoas independentemente de orientação sexual, compondo índices de assassinatos semelhantes aos de guerras civis. A fala de outra/o ativista indica, porém, uma tendência de agravamento da situação quando se foca a população LGBT:

\begin{abstract}
Quando eu estou num determinado local e sou maltratada pela questão da minha identidade e eu vou buscar algo nesse sentido dos direitos, pensando na minha segurança, talvez, porque me senti agredida, o que vem é a questão da minha identidade: 'Mas também, você assim, a culpa é sua...' A culpabilização. Se eu sou vítima, quando eu penso em questão da segurança, eu passo de vítima a agressor. [...] então, isso é muito complicado e isso é no geral, né, não dá pra falar que 'Ah, com as travestis é pior'. [...] A segurança para o Brasil, pra população em geral já é foda, então, e pensar... Então aí fica difícil.
\end{abstract}

Essa convicção de ativistas quanto à intensidade da violência dirigida contra LGBT evidentemente não pode ser comprovada de maneira mais sistemática, entre outras razões, porque o sistema policial ainda não faz o registro adequado de ocorrências contra essa população - à exceção de iniciativas recentes e isoladas -, nem a consequente geração de um banco de dados a respeito dessa realidade.

Nesse contexto, os projetos, programa e iniciativas na área da segurança pública para LGBT podem ser classificados em pelo menos duas modalidades. Por um lado, destacamse os esforços realizados para lidar com as situações de violência já praticadas, como a criação de delegacias especializadas, a atuação da defensoria pública, a regulamentação de visitas íntimas para casais de pessoas do mesmo sexo e a gestão da informação sobre todos esses eventos. Por outro, são crescentes as iniciativas por meio das quais se busca evitar que situações-limite aconteçam. Neste grupo se localizam as leis e atos administrativos, os planos e programas de governo para a população LGBT e as experiências de capacitação de agentes da segurança pública, como bombeiros, guardas e policiais.

A respeito dos casos de violência contra LGBT, um/a 
gestor/a de São Paulo destacou o desafio de criar um sistema que organize as informações já coletadas pela Delegacia de Crimes Raciais e Delitos de Intolerância (Decradi), que, segundo ela/e, possui uma enorme quantidade de registros de intolerância homofóbica e que poderia ser fonte de pesquisa para o Brasil inteiro. Segundo duas/dois outras/os gestoras/es de órgãos federais, esse sistema já existe, pelo menos no estado do Rio de Janeiro, onde acontece um treinamento para tipificar as ocorrências de crimes contra LGBT, disponibilizando essa informação para todo o país. Segundo eles/as, a proposta é expandir essa medida para outras regiões, com base na experiência do Rio de Janeiro, detalhada nos seguintes termos por um/a gestor/a deste estado:

No registro de ocorrência policial, você tem agora, no campo motivação do crime, 'discriminação contra $L G B T$ ', 'discriminação e violência contra LGBT'. E isso a gente passou quanto tempo? Um ano debatendo com a Secretaria de Segurança Pública, como que ia ser se isso podia, se isso era uma autodiscriminação e não sei o quê... Mas como também proteger a comunida-de, também, porque queriam botar orientação sexual de todo o individuo que fosse registrar a ocorrência. Agora o que tem a ver um indivíduo que vai registrar a ocorrência? Às vezes não tinha nada a ver, relacionado com homofobia diretamente, você botar orientação sexual. E será que todo individuo ia querer ter a sua orientação sexual registrada no boletim de ocorrência? Isso foi todo um debate. No final, o que ficou? Ficou de que era necessário entrar na motivação do crime, porque aí era o crime relacionado, não necessaria-mente o denunciante é gay ou é lésbica.

Parece bastante relevante, no relato acima, o fato da decisão ter sido fruto de um debate envolvendo diversos segmentos afetados, bem como a orientação de registrar "discriminação contra LGBT" apenas no campo da motivação de determinada ocorrência, de modo que não se transforme o que seria um mecanismo de proteção em mais uma modalidade de eventual constrangimento. Ainda que esse tema não seja objeto de nenhuma ação programática do Plano Nacional de Promoção da Cidadania e Direitos Humanos de LGBT, ${ }^{47}$ uma proposta relativa a ele havia sido aprovada na Plenária Final da I Conferência Nacional LGBT, em 2008:

Pactuar, elaborar e consolidar pesquisas, informações e estatísticas, com recorte de orientação sexual e identidade de gênero e as especificidades quanto aos tipos de crimes de homofobia praticados, no âmbito 
${ }^{48}$ BRASIL, 2008c, p. 29.

${ }^{49}$ BRASIL, $2010 \mathrm{~b}$.

${ }^{50}$ BRASIL, 2008d, não paginado.

${ }^{51}$ BRASIL, 2008d, não paginado. do Sistema Nacional de Estatística de Segurança Pública e Justiça Criminal; bem como estabelecer a identificação de gênero e agressão sofrida pela vítima regulamentada em lei para ocorrência nas delegacias, criando mecanismos que possibilitem identificar com maior precisão os crimes homofóbicos, através da qualificação dos peritos e operadores da Segurança Pública. ${ }^{48}$

Outro tema que vem gerando debate é o direito à visita íntima para integrantes da população LGBT que estejam cumprindo pena. No Pará, esse assunto já foi objeto de decisão administrativa, uma vez que as visitas íntimas para casais do mesmo sexo foram regulamentadas pela Portaria n. 1.299, emitida pela Superintendência do Sistema Penitenciário do Estado do Pará, em 30 de novembro de 2009. O problema agora é saber o alcance dessa medida, como refletiu um/a ativista de outro estado, que se mostrou bastante cética/o quanto à eficácia da iniciativa: "Entre o decreto e a aplicação da visita íntima de fato, lá na penitenciária, há um distanciamento imenso."

O tema das visitas íntimas para casais do mesmo sexo em situação de encarceramento aparece também no Programa Nacional de Direitos Humanos 3 (PNDH 3), que apresenta uma proposta de regulamentação da questão na Lei de Execução Penal. ${ }^{49}$ Não é demais lembrar, ainda, que a Portaria n. 1.190, de 19 de junho de 2008, do Ministério da Justiça, que "Regulamenta a visita íntima no interior das penitenciárias federais", ${ }^{50}$ não restringe explicitamente o direito à visita aos casais de pessoas de sexo diferente, como se observa em seu artigo segundo, parágrafo primeiro, o qual estabelece: "O registro de cônjuge ou companheira(o) de comprovado vínculo afetivo deverá ser realizado pela direção do estabelecimento prisional onde se encontrar o preso." 51 Numa interpretação extensiva, portanto, o direito poderia também ser assegurado a casais de pessoas 'do mesmo sexo', sem necessidade de qualquer nova regulamentação da matéria.

Outra questão objeto de discussão no âmbito das demandas relativas à segurança da população LGBT diz respeito à criação ou não de delegacias especializadas no atendimento a tal população. Há ativistas que defendem a necessidade de criação de tais delegacias exclusivas, enquanto outras/os propõem a implementação de uma política pública que assegure a qualidade do referido atendimento em todas as delegacias policiais, sem segregação.

Algumas/ns gestoras/es e ativistas do Piauí mencionaram como uma conquista a criação da Delegacia de Defesa e Proteção dos Direitos Humanos e Repressão às Condutas Discriminatórias, formalizada pelo governo do 
${ }^{52}$ Cabe mencionar que, até o presente momento, não foi divulgado oll Plano Nacional LGBT, que seria fruto da II Conferência Nacional LGBT, ocorrida em Brasília no final de 2011 . estado por meio da Lei Complementar n. 51, de 23 de agosto de 2005. Segundo um/a ativista, embora não exclusivamente voltada para a população LGBT, essa delegacia tem o mérito de investigar casos de 'violência homofóbica', frequentemente negligenciados pelas delegacias comuns:

Nós já temos delegacia, que embora não seja específica, mas que atende à população, coisa que não acontecia antigamente. Hoje a gente já tem. Recentemente mesmo nós tivemos um caso de agressão a um grupo de travestis, que foram várias vezes na delegacia comum, normal, e não foram atendidas. Foram lá na delegacia que atende às práticas discriminatórias e o caso delas foi aceito, foi levado adiante, o processo tá seguindo, tá dando prosseguimento às investigações, às apurações do fato.

Mesmo sendo avaliada como uma conquista, essa delegacia não é isenta de críticas, como se depreende da fala de outra/o ativista quanto ao sentido segregacionista que a medida pode ter:

A gente defende por entender que ela [a delegacia] tem o mesmo papel que, por exemplo, a Delegacia da Mulher tem tido ao longo dos tempos. É como a política de cotas, como algo que é transitório. Aliás, até o governo, na inauguração da delegacia, fez uma fala muito interessante. Ele disse que o desejo dele era que não precisasse inaugurar essa delegacia, que essa delegacia não precisasse existir.

Observa-se que essa questão da criação ou não de delegacias especializadas ou exclusivas também não aparece em nenhuma das ações programáticas do Plano Nacional LGBT, embora tenha sido objeto de várias propostas aprovadas na Plenária Final da I Conferência Nacional LGBT, ${ }^{52}$ as quais sinalizam que não houve consenso quanto à matéria entre as/os delegadas/os presentes, embora tenha prevalecido um número maior de propostas que apontam no sentido de evitar-se o atendimento segregado de LGBT em delegacias especializadas.

Note-se ainda que a questão da criação de delegacias especializadas tampouco aparece entre as ações previstas no Programa Brasil sem Homofobia (2004) e no PNDH 3 (2009), enquanto, no Programa Nacional de Direitos Humanos 2 (PNDH 2), de 2002, o entendimento prevalecente apontava no sentido do atendimento especializado para LGBT.

Além do registro de ocorrências policiais por homofobia nas delegacias do Rio de Janeiro e da existência de delegacias especializadas em alguns estados (SP, RS e PI), entre os/as entrevistados houve ainda referência, no âmbito das ações de combate à homofobia relativas à área de 
segurança pública, à atuação da defensoria pública em três estados (PA, PI e SP). No Piauí, esse órgão tem um núcleo especializado no atendimento a vítimas de discriminação, e, em São Paulo, segundo relato de um/a gestor/a, há uma parceria entre o governo municipal e a Defensoria Pública para o atendimento de vítimas de homofobia:

Nós conseguimos estabelecer um termo de cooperação técnica com a Defensoria Pública, para que os defensores também passassem a atuar na defesa da Lei 10.948. Então, se o cidadão ou a cidadã era vítima de homofobia, a gente encaminhava, pelo Centro de Combate à Homofobia, pra Defensoria, e a Defensoria designava o defensor que ia fazer todo o processo na Secretaria da Justiça.

Por outro lado, no âmbito do universo geográfico da pesquisa, foi identificado um conjunto de leis e decretos estaduais e municipais que prevê sanções civis para a discriminação por orientação sexual, conforme o Quadro 1.

Quadro 1: Atos normativos (leis, decretos ou resoluções), relativos à proibição de discriminação por orientação sexual, por unidades da federação

\begin{tabular}{|c|c|c|c|c|c|c|c|c|c|c|c|c|}
\hline \multirow[t]{2}{*}{ Iniciativa } & & \multicolumn{10}{|c|}{ Unidades da Federação } & \multirow[t]{2}{*}{ Total } \\
\hline & & AM & PA & $\mathrm{CE}$ & $\mathrm{PI}$ & DF & GO & RJ & SP & PR & RS & \\
\hline Combate & Lei & $x$ & $x$ & & $x$ & $x$ & & $x$ & $x$ & & $x$ & 7 \\
\hline à discriminação & Decreto & & & & $x$ & & & & $x$ & & & 2 \\
\hline $\begin{array}{l}\text { por orientação } \\
\text { sexual }\end{array}$ & Resolução & & & & & & & & $x$ & & & 1 \\
\hline
\end{tabular}

Fonte: UFG, 2010, p. 17.

Do ponto de vista cronológico, percebe-se um maior número de leis e atos administrativos na primeira década do século XXI, que concentra mais de $80 \%$ da legislação identificada, com ênfase para os anos 2000 a 2004, quando metade dela foi sancionada. É importante registrar que, apesar de relevantes, essas leis e atos administrativos possuem limitações. Em primeiro lugar, pela distância que existe entre a criação e a aplicação de determinada lei ou decreto, particularmente quando se considera que legislar sobre direito penal é competência privativa da União, conforme artigo 22, I, da Constituição Federal. Em segundo lugar, dada a inexistência de legislação federal de criminalização da homofobia, tema abordado por diversas pessoas entrevistadas, tais instrumentos normativos estaduais e municipais tendem a ter um alcance e uma eficácia limitados. 
${ }^{53}$ BRASIL, $2010 \mathrm{C}$.

${ }^{54}$ BRASIL, 2008b.

${ }^{55}$ BRASIL, 2009.

${ }^{56}$ BRASIL, $2010 \mathrm{~b}$.
${ }^{57} \mathrm{Em} 3$ de julho de 2013, por meio da Portaria n. 766, o Governo Federal criou o Sistema Nacional de Promoção de Direitos e Enfrentamento à Violência contra Lésbicas, Gays, Bissexuais e Transexuais (Sistema Nacional LGBT) visando articular diferentes experiências de políticas públicas de combater à violência que atinge tais sujeitos.

${ }^{58}$ Cláudio Nascimento SILVA 2007, p. 3.
A despeito da inexistência de um marco legal em nível federal, o tema da segurança pública para a população LGBT está presente em tentativas de resposta do Governo Federal a demandas do movimento LGBT, por meio da incorporação de propostas à agenda governamental de direitos humanos, materializada em documentos como o Programa Nacional de Direitos Humanos 2 (PNDH 2),53 o Programa Brasil Sem Homofobia; ${ }^{54}$ o Plano Nacional de Promoção da Cidadania e Direitos Humanos de LGBT (PNPCDH-LGBT); ${ }^{55} \mathrm{e} 0$ Programa Nacional de Direitos Humano 3 (PNDH 3). ${ }^{56}$

Observando a cronologia desses documentos e o que dizem sobre segurança, destaca-se que, em 2004, foi publicado o Brasil sem Homofobia, que tem, em sua estrutura, 11 campos de ação, entre eles um que trata do "Direito à segurança: combate à violência e à impunidade", com cinco ações: a) elaboração de diretrizes para os planos de segurança nacional, estadual e municipal, visando às ações de combate à violência; b) capacitação e qualificação de policiais para o acolhimento das pessoas e demandas LGBT; c) criação de centros de referência contra a discriminação, na estrutura das secretarias de segurança pública; d) diagnóstico e avaliação da situação de violação aos direitos humanos de homossexuais e de testemunhas de crimes relacionados à orientação homossexual; e e) criação de uma câmara técnica para diagnosticar, elaborar e avaliar a promoção das políticas de segurança na área em questão. Até o momento, entretanto, o que se observa é que parte expressiva das ações do BSH ainda não foi implementada, enquanto outras ainda se encontram em estágio embrionário, a exemplo das relativas à capacitação de profissionais e da criação dos centros de referência vinculados às secretarias de segurança pública estaduais. ${ }^{57}$

Três anos depois da publicação do Brasil sem Homofobia, uma iniciativa da sociedade civil apoiada pelo Governo Federal representou um marco no campo da segurança pública para LGBT, que foi o I Seminário Nacional de Segurança Pública e Combate à Homofobia, realizado em 2007, com o slogan foi "Unindo esforços, ampliando diálogos". Um dos principais objetivos do seminário foi a "construção coletiva de diretrizes para a criação do Plano Nacional de Segurança Pública para o Enfrentamento da Homofobia". ${ }^{58}$ Foram elaboradas neste evento 62 propostas, organizadas em cinco eixos: (1) formação policial: culturas das instituições e diversidade sexual; (2) prevenção à violência contra LGBT: experiências policiais e comunitárias; (3) violências específicas e políticas diferenciadas de prevenção e segurança; e (5) monitoramento, avaliação e controle social das políticas de segurança para LGBT. Apesar do ineditismo e da densidade das propostas, o referido Plano Nacional de 
${ }^{59}$ BRASIL, 2009

${ }^{60}$ BRASIL, 2009

Segurança Pública para o Enfrentamento da Homofobia até o momento não foi institucionalizado pelo Governo Federal.

Dois anos após o I Seminário Nacional de Segurança Pública e Combate à Homofobia, em maio de 2009, a Secretaria de Direitos Humanos da Presidência da República (SDH) apresentou o Plano Nacional LGBT, como desdobramento da $1^{a}$ Conferência Nacional LGBT, trazendo diretrizes e ações para a elaboração de políticas públicas para essa população. ${ }^{59}$ Das 51 diretrizes, cinco abordam de modo mais específico direitos da população TBGL LGBT no campo da segurança pública: a) promoção da denúncia de toda e qualquer atitude de discriminação à população LGBT; b) combate à violência doméstica e familiar contra LGBT; c) implementação de uma política de enfrentamento à homofobia em todas as unidades de custódia (casas de custódia e penitenciárias), assegurando às/aos custodiadas/ os o direito de optarem por celas distintas ou serem encaminhados para unidades condizentes com seu gênero social (leia-se sua identidade de gênero); d) execução de ações de vigilância, prevenção e atenção à violência contra lésbicas, gays, bissexuais, travestis e transexuais; e e) apoio do Governo Brasileiro, nos fóruns internacionais, a iniciativas de defesa dos direitos humanos que denunciem as práticas de prisão, tortura ou pena de morte contra a população LGBT em vários países. Sob as 51 diretrizes, o Plano Nacional LGBT foi estruturado a partir de dois eixos, que se subdividem em um conjunto de 10 estratégias com 180 ações, das quais pelo menos 42 têm conexão com o campo da segurança pública. ${ }^{60}$

Ao final de 2009, foi divulgado o PNDH 3, nos termos do Decreto n. 7.037, assinado pelo Presidente da República, em que se encontram sete ações relativas à segurança pública para a população LGBT, entre as quais se destacam: produção de relatório de acompanhamento das políticas contra a discriminação; promoção de campanhas e pesquisas voltadas ao combate à violência; estruturação de sistema nacional de vítimas de tráfico de pessoas; e encaminhamento para o presídio feminino de mulheres transexuais e travestis que estejam em regime de reclusão. Comparadaa ao PNDH 2, aprovado em 2002, a versão atual amplia de quatro para sete o número de ações na área de segurança para a população LGBT. Os temas novos abordados nesta versão são as ações em torno da situação de encarceramento, incluindo direito à visita íntima e a previsão de apoio a vítimas de tráfico de pessoas.

Também foram identificadas, no levantamento de dados, três portarias e uma ferramenta de gestão educacional e pedagógica do Governo Federal, que têm relação com a área de segurança para a população LGBT: 
${ }^{61}$ BRASIL, 2010 f, não paginado.

${ }^{62}$ BRASIL, $2010 \mathrm{~d}$. a Portaria n. 21, de 10 de julho de 2009, a Portaria n. 25, de 25 de agosto de 2010, e a Portaria n. 26 , de 26 de agosto de 2010, todas da Secretaria Nacional de Segurança Pública (Senasp), do Ministério da Justiça, que versam sobre o mesmo tema. A primeira institui o Grupo de Trabalho para diagnosticar, elaborar e avaliar a promoção das políticas de segurança para população LGBT, a segunda cria efetivamente esse Grupo de Trabalho, nomeando suas/seus integrantes, enquanto a terceira dispõe sobre o "Regimento Interno do Grupo de Trabalho para promover Políticas Públicas de Segurança Pública à População de Lésbicas, Gays, Bissexuais, Travestis e Transexuais (LGBT)". ${ }^{61}$

A ferramenta de gestão educacional e pedagógica acima mencionada é a Matriz Curricular para Ações Formativas dos Profissionais da Área de Segurança Pública, também da Senasp, criada em 2003, revista e ampliada em 2009, cuja pretensão é ser um referencial para orientar a formação da Polícia Militar, Polícia Civil e Bombeiros Militares, independentemente da instituição ou modalidade de ensino. ${ }^{62}$

A partir de referências ao Brasil sem Homofobia, ativistas entrevistadas/os que abordaram o tema da segurança relataram a criação de programas em dois dos 10 estados pesquisados (Pará sem Homofobia e Rio de Janeiro sem Homofobia), embora não tenham sido identificados instrumentos legais que formalizem os respectivos programas. Algumas ativistas entrevistadas/os também mencionaram a criação, em 2005, da Câmara Técnica Brasil sem Homofobia, dentro no âmbito da Secretaria Nacional de Segurança Pública. Por outro lado, reclamou-se da pouca estrutura e de certa desmobilização desse programa, além de certa limitação de seu alcance nos estados, como comentou um/a ativista:

\begin{abstract}
A gente não nota isso capilarizado, digamos assim, na Secretaria de Justiça. Muito menos nas atividades da polícia militar ou da polícia civil, com exceção da polícia civil aqui de uma delegacia que combate crimes de intolerância [...] Mas é algo isolado. Não se nota uma política pública, uma preocupação, governamental, de Estado com relação a esses temas também na segurança pública.
\end{abstract}

Embora se reconheçam os limites dos projetos, programas e iniciativas, parece procedente a reflexão feita por um/ a ativista do Pará a respeito do Plano de Segurança Pública e Combate à Homofobia daquele Estado: "Ele ainda é uma peça literária, mas é melhor que não ter nada nem escrito".

\section{Problemas e desafios}

As dificuldades de interação entre os diversos níveis e instâncias de governo e deste com a sociedade civil, a falta 
de uma política pública de Estado e a chamada 'homofobia institucional' compõem a tríade estrutural de problemas e desafios na área de segurança pública identificada nesta pesquisa, a partir dos relatos de entrevistados/as. Nas respostas dadas acerca da relação entre níveis e instâncias de governo, bem como do governo com a sociedade civil no tocante à segurança pública, o que mais chama a atenção é a discrepância entre os quadros pintados por entrevistadas/ as, predominando as opiniões críticas por parte de ativistas e as visões mais otimistas, por partes dos/as gestores/as.

Assim como há análises negativas críticas de ativistas do movimento social em relação à atuação geral do Governo Federal, existem também críticas na direção contrária, como ilustra a declaração de um/a gestor/a, que trouxe para a discussão o problema da legitimidade de certas reivindicações, como a criação de alas específicas para travestis que cumprem pena. Esse/a gestor/a alega que há discrepância quando se confronta a demanda do movimento social com dados apurados pelo próprio governo em pesquisas com os indivíduos que seriam beneficiados por esta medida:

Fazer de porta-voz dos outros sem ser autorizado a isso é muito estranho. Isso é difícil pra quem está lá dentro, e a gente precisa ouvir quem está lá dentro. O que é que eles precisam? Por exemplo, a gente já sabe que os gays, num levantamento prévio que a ouvidoria realizou, informalmente, porque não há nenhum dado publicado, os gays gostariam de ter um espaço reservado pra eles. As travestis não querem. As travestis querem continuar nos espaços masculinos, o que é inclusive um contrassenso quando você vai para a teoria de que travesti quer ter um gênero feminino e aí você... e aí elas querem ser mantidas... aquelas que foram ouvidas.

Assim como é complexa a relação do governo com a sociedade civil (considerando-se que na atualidade há sujeitos oriundos dos movimentos sociais com atuação no próprio governo, assumindo cargos de gestão, o que inclusive complexifica bastante a dicotomia ativistas $\mathrm{x}$ gestores/as aqui apontada), também não se podem classificar, como simples, as relações entre as instâncias governamentais distintas (federal, estaduais e municipais) e, dentro de uma mesma instância, o relacionamento entre os diversos órgãos no que diz respeito à desejada sinergia para o estabelecimento de ações e políticas para a população LGBT. Um dos poucos relatos positivos de integração entre órgãos de governo foi feito por um/a gestor/a do Rio de Janeiro, referindo-se ao bom relacionamento entre uma instância estadual e outra federal no campo da segurança pública. 
Outro/a gestor/a estadual falou sobre a necessidade de transversalizar o tema da segurança pública para a população LGBT, estendendo essa discussão para além dos órgãos públicos especializados. Segundo ela/e, essas questões não devem ser tratadas apenas por alguns órgãos e esquecidas por outros. Nessa fala, foi destacada a importância de ações para a população LGBT serem implementadas, por exemplo, nas secretarias de segurança, de justiça e do trabalho, entre outras, como uma política que perpasse todas as instâncias do governo, ao invés de ser designada à responsabilidade apenas de um órgão especializado, necessário, mas insuficiente, se estruturado sem articulação intra e intergovernamental.

A falta de transversalização do tema da segurança pública e a concentração das ações em alguns órgãos apontam para a falta de uma políica pública de Estado, no sentido estrito do termo, que pressupõe existência de amparo legal e continuidade das ações, dotação orçamentária, controle social, entre outros elementos constitutivos. A mais elementar das fragilidades, entretanto, diz respeito às ações isoladas ou tímidas, como ilustra um/a ativista:

Em nível de município, nós temos ações tímidas, como o Disque Cidadania, que está precarizado, tá quase no esquecimento. É uma política que funcionou bem no início, mas que agora tá muito precarizada.

Esse conjunto de predicados de uma política pública de Estado que faltam às iniciativas na área de segurança para a população LGBT são agravados por atitudes e posições que muitas vezes denotam preconceito por parte dos próprios agentes públicos, que parece se inscrever na própria estrutura governamental, o que nos leva a pensar na existência do que vem sendo produzido discursivamente pelo movimento LGBT como 'homofobia institucional'. Há sinais de mudança, porém, como relatou um/a gestor/a estadual, embora o cenário ainda esteja marcado por muitos desafios a serem superados, nas três esferas de governo:

Quando nós discutimos algumas situações concretas que envolvem o sistema de segurança pública, já se tornou comum a presença, por exemplo, dos profissionais do sexo nessas discussões. Então, a presença de uma travesti que tá na rua, numa mesa de reunião onde você encontra um coronel-comandante de um batalhão, um delegado titular de uma delegacia regional, e ali ela ter a oportunidade de ser ouvida, isso já faz uma diferença.

De fato, a presença de representantes das pessoas afetadas por determinada situação de exclusão social na mesa de negociação junto com os agentes responsáveis por conduzir políticas públicas faz toda uma diferença expressiva.

314 Estudos Feministas, Florianópolis, 22(1): 297-320, janeiro-abril/2014 
A considerar os relatos obtidos nesta pesquisa, entretanto, essas situações não são apenas raras, mas também bastante insignificantes quando comparadas com as muitas ações que denotam homofobia praticada especialmente pelas forças policias que, segundo um/a ativista, são as que deveriam estar nos protegendo e que, na verdade, muitas vezes são as/os nossas/os agressoras/es. Essa realidade de violências dirigidas à população LGBT também foi apontada com tintas fortes por muitas/os outras/os ativistas, que qualificaram as práticas da segurança pública local (de seus municípios e estados) como "violentas e higienistas" e relacionaram a atuação dos órgãos de segurança do Brasil à herança do período ditatorial, como se observa no trecho seguinte de entrevista:

Você percebe ainda um ranço muito forte da ditadura no Brasil, em especial nas Forças Armadas e nas polícias militares. Então, ainda é muito difícil pra essas instituições ceder um espaço de interlocução com a sociedade para construção de novas políticas, que inclusive mudem o olhar do que é segurança pública. [...] Uma vez eu escutei um policial dizer pra mim que é um absurdo veado entrar pela porta da frente da delegacia

Outra/o ativista destacou o tema da 'cultura das organizações de segurança pública', afirmando que as conversas entre representantes do movimento LGBT e dos órgãos públicos ainda não chegaram aos grupos profissionais que estão em início de carreira e atuam mais diretamente nas ruas, onde predomina a mais explícita e agressiva a homofobia.

\section{Considerações finais}

Nunca se teve tanto, e o que há é praticamente nada. Este é o paradoxo com o qual concluem-se as reflexões iniciais sobre políticas públicas para a população LGBT no Brasil, a partir do relatório da pesquisa finalizada em 2011. Essa ambivalência faz-se presente, também, no que tange à área de segurança para a população LGBT no Brasil, a partir do inventário de eventos, documentos, legislações e atos de governo, bem como da escuta atenta de sujeitos entrevistados nesta pesquisa.

Atendimento adequado à população LGBT envolvida em situações de violência, em delegacias especializadas ou não; criação de núcleos de atenção aos direitos de LGBT no âmbito das defensorias públicas dos estados; regularização do direito à visita íntima para casais de pessoas do mesmo sexo; e a criação de um campo nos boletins de ocorrência para registro da homofobia como motivação de crime. Todas são iniciativas necessárias, mas insuficientes para fazer 
frente ao quadro de violência e discriminação que deu origem a essas discussões e iniciativas. Isso leva, inclusive, a se ponderar que, talvez, a questão das violências dirigidas à população LGBT (e, assim, de seu enfrentamento) extrapole as possibilidades de atuação governamental em seus marcos jurídicos, uma vez que há dimensões do preconceito e da discriminação heterossexista culturalmente arraigados, produzidos e reproduzidos no cotidiano.

O mesmo se pode dizer das leis e atos administrativos que parecem vislumbrar uma legislação federal apenas quando as muitas iniciativas locais, e, portanto, de alcance limitado, sugerirem suficiente consenso social em torno da necessidade de criminalização da violência homofóbica. A discriminação por orientação sexual, por exemplo, já conta com algum tipo de punição, na esfera civil, em leis aprovadas em sete das 10 unidades da federação investigadas. Entretanto, isso ainda não foi o bastante para que o Congresso Nacional aprovasse e a Presidência da República sancionasse o Projeto de Lei n. 122/2006, que prevê punição para a 'violência homofóbica'. O caráter recente dessas leis e atos administrativos regionais talvez explique essa lacuna, uma vez que $80 \%$ da legislação identificada nesta pesquisa foi sancionada há menos de 10 anos. Tudo isso ilustra a vigência do conservadorismo de matriz religiosa que, se não controla, interfere decisivamente nos debates acerca dos direitos sexuais no Brasil e no mundo, comprometendo a constitucional laicidade do Estado brasileiro, o que tem dificultado a implementação de operacionalização de políticas públicas mais efetivas no campo dos direitos humanos, sobretudo no que tange aos direitos da população LGBT.

Talvez o dado mais animador seja o aumento e a politização do debate em torno do tema, expresso nos espaços públicos de interlocução entre governo e sociedade civil, como o l e o Il Seminário Nacional de Segurança Pública e Combate à Homofobia (2007 e 2010), a l e a ll Conferência Nacional LGBT (2008 e 2011) e a Conferência Nacional de Segurança Pública (2009). Das discussões realizadas nesses fóruns, deriva um número crescente de iniciativas no campo da segurança pública para a população LGBT, que permite nomear as situações de violência e apresentar proposições que podem, a médio prazo, resultar em ações de Estado que atendam aos requisitos de políticas públicas, quanto à suporte legal, previsão orçamentária, perenidade e controle social.

O número e a complexidade das propostas surgidas destes eventos parecem repercutir diretamente no volume e na qualidade das diretrizes e ações propostas em documentos do Governo Federal, como o Programa Nacional de Direitos Humanos 3 (PNDH3), o Plano Nacional de Promoção 
${ }^{63}$ BRAZIL, 2010g

da Cidadania e Direitos Humanos de LGBT e o Programa Brasil sem Homofobia. A efetivação dessas propostas, entretanto, ainda é bastante inconsistente em termos de alcance e de escala, como se pode perceber no Relatório de Monitoramento do Plano Nacional LGBT, ${ }^{63}$ em que cartilhas e cursos de poucas horas e para poucas pessoas são tomados como evidência da efetivação de uma ação que pretende lidar com problemas estruturais e endêmicos, como a chamada, nos discursos de ativistas, "homofobia de Estado". Por fim, a discussão aqui trazida, à luz das falas de ativistas e gestores/as entrevistados/as, aponta para a necessidade de que a temática da segurança pública para a população LGBT seja tida como uma responsabilidade progressivamente compartilhada entre o Estado e a sociedade civil, materializada na criação de espaços formais de debate, deliberação e controle tanto do que caracteriza quanto do que viabiliza a superação da realidade de violência e discriminação a que está exposta a população LGBT, por meio do reconhecimento da inalienável dignidade dessas pessoas e da conquista da cidadania plena por elas próprias.

\section{Referências}

BORRILLO, Daniel. Homofobia. Espanha: Bellaterra, 2001.

BRASIL. Conselho Nacional de Combate à Discriminação SEDH. Brasil sem Homofobia: Programa de Combate à Violência e à Discriminação contra GLTB e de Promoção da Cidadania Homossexual. Brasília: SEDH, 2008b.

Constituição: República Federativa do Brasil, 1988. Brasília: Ministério da Educação, 1989.

- Ministério da Justiça. Secretaria Nacional de Segurança Pública. Portaria n. 2b, de 26 de agosto de 2010. Brasília, SENASP, 2010 f. Não paginado.

. Ministério da Justiça. Matriz curricular para ações formativas dos profissionais da área de segurança pública. 2010d. Disponível em: <http://tinyurl.com/ phmeye5 >. Acesso em: 3 jun. 2010.

Ministério da Justiça. Portaria n. 1.190, de 19 de junho de 2008. 2008d. Disponível em: <http://tinyurl.com/ lo3scuc >. Acesso em: 3 abr. 2014.

Ministério da Justiça. Segurança pública: estatísticas. 2010e. Disponível em: <http://tinyurl.com/p89sy5m>. Acesso em: 3 jun. 2010 e.

Ministério da Saúde. Temático Prevenção de Violência e Cultura de Paz III. Brasília: Organização Pan-americana de Saúde, 2008a.

. Programa Nacional de Direitos Humanos - PNDH 2.

2010c. Disponível em: <http://portal.mj.gov.br/sedh/pndh/ 
pndhll/Texto\%20Integral\%20PNDH\%20ll.pdf>. Acesso em: 28 fev. 2010.

. PRONASCl: Programa Nacional de Segurança Pública com Cidadania. [2014]. Disponível em: < http://tinyurl.com/ o8brjho>. Acesso em: 5 abr. 2014.

. Secretaria de Direitos Humanos. Ministro da Justiça recebe Conselho Nacional LGBT e cria GT para monitorar tramitação do PLC 122. 2013b. Disponível em: <http:// tinyurl.com/ogl5r4y>. Acesso em: 16 ago. 2013.

Secretaria de Direitos Humanos. Relatório de Monitoramento das Ações do Plano Nacional de Promoção da Cidadania e Direitos Humanos de Lésbica, Gays, Bissexuais, Travestis e Transexuais. Brasília: SHD, 2010g.

. Secretaria de Direitos Humanos. Relatório sobre violência homofóbica no Brasil: ano de 2011. [2012]. Disponível em: <http://www.abglt.org.br/docs/Relatorio-LGBT_SDH. pdf $>$. Acesso em: $18 \mathrm{dez} .2012$.

Secretaria de Direitos Humanos. Relatório sobre violência homofóbica no Brasil: ano de 2012. [2013a]. Disponível em: <http://www.sdh.gov.br/assuntos/lgbt/pdf/relato rio-violencia-homofobica-ano-2012>. Acesso em: 5 mar. 2013. Secretaria Especial de Direitos Humanos. Anais da Conferência Nacional de Gays, Lésbicas, Bissexuais, Travestis e Transexuais - GLBT. Brasília: SEDH, 2008c.

Secretaria Especial dos Direitos Humanos da Presidência da República. Plano Nacional de Promoção da Cidadania e Direitos Humanos de LGBT. Brasília: SEDH, 2009.

Secretaria Especial dos Direitos Humanos da Presidência da República. Programa Nacional de Direitos Humanos (PNDH 3). Brasília: SEDH/PR, $2010 \mathrm{~b}$.

[Site do Ministério da Justiça]. 2010a. Disponível em: $<$ http://tinyurl.com/oqs5blf > . Acesso em: 3 abr. 2010.

CIARALLO, Cynthia; NASCIMENTO, Andréa. "Segurança pública e psicologia: pelo fortalecimento de laços sociais conscientes e solidários na garantia dos direitos humanos". Cadernos temáticos da Conseg, Brasília, ano I, n. 7, p. 1219, 2009.

DHNET. O crime homofóbico. 2010. Disponível em: <http:// www.dhnet.org.br/dados/manuais/dht/br/mott_assassinatos_h/ 01_crime.html >. Acesso em: 10 ago. 2010.

FACCHINI, Regina. Sopa de letrinhas? Movimento homossexual e produção de identidades coletivas nos anos 90 . Rio de Janeiro: Garamond, 2005.

FONTOURA, Natalia de Oliveira; RIVERO, Patrícia Silveira; RODRIGUES, Rute Imanishi. "Segurança pública na Constituição Federal de 1998: continuidades e perspectivas". In: BRASIL. Políticas Sociais: acompanhamento e análise. Brasília: IPEA, [2009]. p. 135-196. v. 3. 
GIDDENS, Anthony. Modernidade e identidade. Rio de Janeiro: Jorge Zahar, 2002.

GUARESCHI, Neuza et al. "Problematizando as práticas psicológicas no modo de entender a violência". In: STREY, Marlene N.; AZAMBUJA, Mariana P. Ruwer; JAEGER, Fernanda Pires (Org.). Violência, gênero e políticas públicas. Porto Alegre: EDIPUCRS, 2004. p 177-193.

ILGA. Relatório 2008: homofobia patrocinada pelo Estado. 2010. Disponível em: <http://ilga.org/ilga/pt/article/1 165>. Acesso em: 3 abr. 2010.

MARIANO, Benedito Domingos. "Aspectos históricos do Sistema de Segurança Pública no Brasil e sua organização na atualidade". Cadernos temáticos da Conseg, Brasília, ano I, n. 7, 2009. p. 20-25.

MELLO, Luiz et al. "Políticas de saúde para lésbicas, gays, bissexuais, travestis e transexuais no Brasil: em busca de universalidade, integralidade e equidade". Sexualidad, Salud e Sociedad, Rio de Janeiro, n. 9, dic. 2011 . p. 7-28.

MOYA, Thaís S. [Blog em Defesa das Ações Afirmativas]. 2010. Disponível em: <http://emdefesadasacoesafirmativas. blogspot.com/2009/05/acao-afirmativa-e-um-conjuntode.html >. Acesso em: 9 set. 2010.

RUA, Maria das Graças. "As políticas públicas e a juventude dos anos 90". In CNPD: Jovens acontecendo na trilha das políticas públicas. Brasília, 1998. P. 731-752. V. 2.

SANTOS, Emerson Clayton Rosa. Conceito de segurança pública. [2010]. Disponível em: <http://br.monografias.com/ trabalhos2/seguranca-publica/seguranca-publica.shtml \#polit>. Acesso em: 23 jan. 2010.

SCHILLING, Flávia Inês. "Direito à vida, liberdade e segurança". In: MATSUDA, Fernanda Emy; GRACIANO, Mariângela; OLIVEIRA, Fernanda Castro Fernandes. Afinal, o que é segurança pública? São Paulo: Global, 2009. p. 1-13.

SILVA, Cláudio Nascimento (Org.). Diretrizes para o Plano Nacional de Segurança Pública para o Enfrentamento da Homofobia: relatório resumido de propostas do I Seminário Nacional de Segurança Pública e Combate à Homofobia. Rio de Janeiro: Grupo Arco-Íris de Conscientização Homossexual e Movimento D'ELLAS, 2007.

SIMÕES, Júlio Assis; FACCHINI, Regina. Na trilha do arco-íris: do movimento homossexual ao LGBT. São Paulo: Fundação Perseu Abramo, 2009.

UFG. Ser-Tão. Políticas públicas para população LGBT no Brasil: um mapeamento crítico preliminar. Goiás: Ser-Tão, 2010.

[Recebido em 26 de março de 2011 , reapresentado em 11 de novembro de 2013 e aprovado em fevereiro de 2014] 


\section{Security Public Policies for LGBT Population in Brazil}

Abstract: In this article, we present a critical analysis of governmental actions, plans, and programs, regarding public security, directed toward the LGBT population in Brazil. Despite the identification of many proposals and certain ongoing initiatives, some of them planned during public discussions involving the government and the civil society, the final outcome shows an absolute imbalance between homophobic violence and Brazilian governmental actions to change this scenery. This finding helps understand why LGBT people regard the State and its representatives with distrust, in several fields of social life where their civil rights are denied, but especially in the public security sphere, where the nexus between questioning the heterosexual norm and violence is still recurrent.

Key Words: Public Security; LGBT; Homophobia; Public Policy; Brazil. 